\title{
Neonatal levels of acute phase proteins and later risk of non-affective psychosis
}

\author{
RM Gardner ${ }^{1}$, C Dalman², S Wicks ${ }^{2}$, BK Lee ${ }^{3}$ and H Karlsson ${ }^{1}$
}

Mounting evidence suggests that immune disturbances in early life may be implicated in the etiology of non-affective psychoses. Our aim was to assess the levels of neonatal acute phase proteins (APPs), central to innate immune function as well as central nervous system development, in neonatal dried blood spots and their association with later risk of non-affective psychoses. This case-control study included 196 individuals with a verified register-based diagnosis of non-affective psychosis and 502 controls matched on age, sex and hospital of birth. Concentrations of nine different APPs were measured in eluates from dried blood spots using a bead-based multiplex assay. Odds ratios (OR) for non-affective psychoses were calculated for $\log _{2}$-transformed (continuous) as well as tertiles of APP concentrations. In continuous analysis, higher concentrations of two APPs, tissue plasminogen activator (tPA; OR: $0.90,95 \%$ confidence interval (Cl): $0.85-0.96$ ) and serum amyloid P (SAP; OR: $0.88,95 \%$ Cl: $0.78-$ 0.99) were protective in terms of risk of non-affective psychosis. These relationships were not affected by the addition of covariates relevant to maternal health, pregnancy and delivery to the model. Tertile analysis confirmed a protective relationship for higher levels of tPA and SAP, as well as for procalcitonin (highest tertile OR: 0.54, 95\% Cl:0.32-0.91). Our results suggest that persons who develop non-affective psychoses have lower levels of certain APPs at the time of birth. These differences may render individuals more susceptible to infectious diseases or cause deficiencies in pathways critical for neurodevelopment. Translational Psychiatry (2013) 3, e228; doi:10.1038/tp.2013.5; published online 19 February 2013

\section{Introduction}

Despite decades of research, the etiology and pathogenesis of schizophrenia and other non-affective psychoses remain elusive. The strongest risk factor for developing schizophrenia is having a family history of schizophrenia and other mental disorders. ${ }^{1,2}$ Although this is commonly taken as evidence of heritable causes, most individuals (>85\%) with schizophrenia do not have a family history of schizophrenia. ${ }^{3}$ Moreover, no major risk-allele has so far been identified. Minor risk alleles have consistently been reported in the major histocompatibility complex region on chromosome six, ${ }^{4-9}$ which is enriched in genes involved with regulation of the immune response. The findings are in agreement with the large body of literature indicating immune system dysfunction in individuals with schizophrenia or other non-affective psychoses. For example, patients are reported to have an increased incidence of autoimmune diseases, ${ }^{10-12}$ exhibit altered levels of multiple inflammatory mediators (reviewed by Miller et al. ${ }^{13}$ ) and have glial cell activation. ${ }^{14}$ Although some of these changes are observed during the early stages of disease, it is not known whether they are a cause or an effect of disease progression.

The single nucleotide polymorphisms identified as contributing some risk of schizophrenia account for only $23 \%$ of variation in liability to schizophrenia. ${ }^{15}$ Although this percentage could increase with sample size, the polygenic nature of schizophrenia suggests that environmental influences are important in determining whether susceptible individuals manifest the disease. Recent reports suggest that environmental exposures during early life, through childhood and up to the point of first onset may contribute to disease development. For example, maternal exposures to certain infectious agents ${ }^{16-18}$ and dietary antigens ${ }^{19}$ are associated with disease development in the offspring.

Given the range of maternal exposures associated with disease in the offspring, the maternal immune response rather than exposure to specific agents or antigens may mediate the actual risk during early life. This notion is supported by studies of archived maternal sera where high levels of both tumor necrosis factor- $\alpha$ and interleukin (IL)- 8 were associated with the development of psychosis in offspring. ${ }^{20,21}$ Experimental studies also indicate that maternal inflammatory signals, particularly IL-6, can produce behavioral abnormalities in adult offspring. ${ }^{22,23}$ In these models, maternal IL- 6 induces cellular and signaling changes in the placenta, including an upregulation of innate immune response genes. ${ }^{24}$ However, the etiological relevance of these experimental models for human populations is not known. Moreover, no study to date has investigated the neonatal immune system with regard to future risk of disease.

Acute phase proteins (APPs) constitute part of the innate immune response and are produced, primarily in the liver, in response to inflammatory cytokines. ${ }^{25}$ APPs function to promote the recognition and opsonization of infectious agents and infected cells, to increase blood viscosity and clotting potential and to sequester nutrients, which pathogens require

${ }^{1}$ Department of Neuroscience, Karolinska Institutet, Stockholm, Sweden; ${ }^{2}$ Department of Public Health Sciences, Division of Public Health Epidemiology, Karolinska Institutet, Stockholm, Sweden and ${ }^{3}$ Department of Epidemiology and Biostatistics, Drexel University School of Public Health, Philadelphia, PA, USA

Correspondence: Dr H Karlsson, Department of Neuroscience, Karolinska Institutet, Retzius Väg 8, B2:5, Stockholm 171 77, Sweden.

E-mail: hakan.karlsson.2@ki.se

Keywords: acute phase proteins; inflammation; neonate; psychosis

Received 7 Decemeber 2012; accepted 3 January 2013 
to replicate. ${ }^{26}$ From early in the second trimester, the fetal liver can produce APPs in response to cytokines such as IL-6, the inflammatory mediator that most strongly drives the acute phase response. ${ }^{27}$ Although some factors involved in the immune response are actively or passively transported across the human placenta during pregnancy, APPs are not believed to cross the placenta. ${ }^{28}$ Levels of APPs in the neonatal blood can therefore be considered specific indicators of the status of the perinatal innate immune system.

The purpose of the present study was to measure a range of APPs in dried blood spots prospectively collected from neonates who later develop non-affective psychosis and matched control individuals.

\section{Materials and methods}

Study population. The study population for this casecontrol study was selected from individuals born in Sweden between 1975 and 1985. Data on individuals with psychiatric illness were extracted from the National Patient Register that includes all in-patient care in Sweden since 1987 and from the Stockholm psychiatric healthcare registry that includes psychiatric out-patient care since 1997. To be included, cases must be alive, still living in Sweden and diagnosed in Stockholm with non-affective psychoses as in-patients between 1 Jan 1987 and 31 Dec 2003 or as out-patients between 1 Jan 1997 and 31 Dec 2003. Two psychiatric nurses verified that the register diagnoses corresponded to the diagnosis in the records at the psychiatric clinics. Nonaffective psychoses were defined according to the Diagnostic and Statistical Manual of Mental Disorders, Fourth Edition (DSM-IV) and International Classification of Disease (ICD-9 and -10), as described in detail previously. ${ }^{19}$ Of the 696 subjects originally identified (Figure 1), 656 were eligible and were approached through their mental health care giver and invited to participate by an initial letter, followed by up to three letters of reminder. Of these, 237 subjects responded positively and were enrolled (Figure 1).
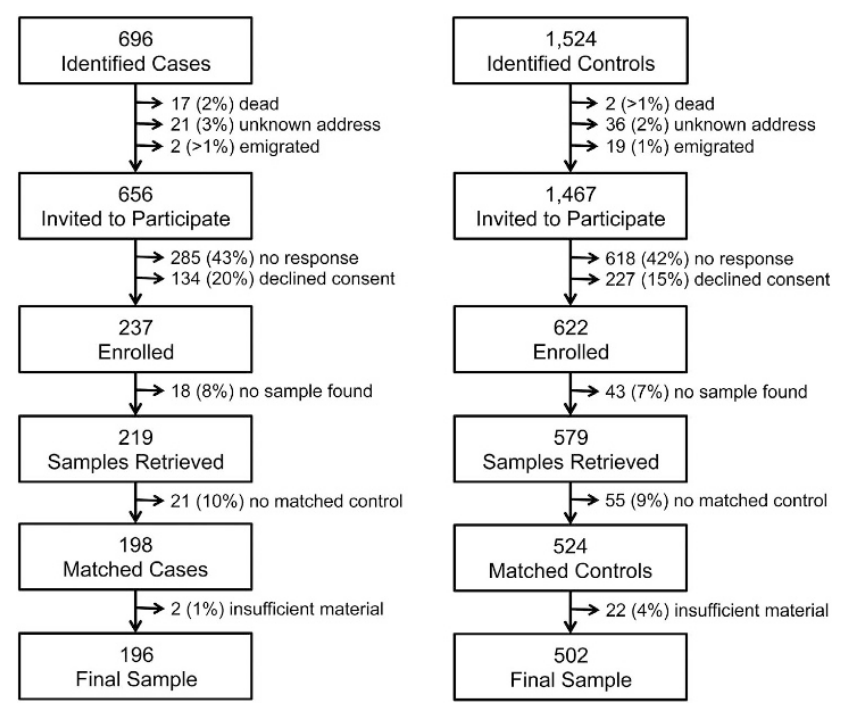

Figure 1 Lost to follow-up.
Comparison individuals were selected from the Swedish Medical Birth Register (MBR), which includes pregnancy outcome data on all children born in Sweden since 1973. Comparison individuals were matched for sex, birthdate and birth hospital. Individuals were included if they were alive on 31 Dec 2003 and had not been treated as in-patients at a psychiatric clinic. Out of the 1524 originally identified subjects, 1467 persons were invited to participate and 622 controls were enrolled (Figure 1).

Written, informed consent was obtained from all the study subjects. The study was approved by the regional research ethics committee at Karolinska Institutet, Stockholm, Sweden.

Blood spots. Since 1975 in Sweden, blood has been collected on a filter from all newborns and stored at a central biobank for screening for metabolic diseases (for example, phenylketonuria). For this study, one blood spot (or a portion thereof) for each consenting participant was excised and transferred to individual plastic re-sealable bags. After matching and subsequent to our previous analyses, there was sufficient material to conduct further analysis for a final sample of 196 cases and 502 matched controls (Figure 1), matched at a ratio varying from 1:1 to $1: 5$.

Analysis of APPs. During sample processing, all personnel were blind to case-control status of the filters. A 3.2- $\mathrm{mm}$ diameter disc was punched from each blood spot and distributed in 96-well plates. Discs were immersed in $80 \mu \mathrm{l}$ of phosphate-buffered saline containing $1 \%$ bovine serum albumin and $0.05 \%$ Tween and incubated at room temperature with gentle agitation for $1 \mathrm{~h}$. One punch from a blank, never-used phenylketonuria filter was included in a randomized location on every plate to function as a negative control. Eluates were stored at $-80^{\circ} \mathrm{C}$ until analysis. Eluates were analyzed for the concentration of nine APPs using a premixed, magnetic bead-based multiplex panel (BioRad, Hercules, CA, USA), according to the manufacturer instructions. In order to fall within the analytical range, eluates were diluted 1:80 using phosphate-buffered saline with $1 \%$ bovine serum albumin for analysis of $\alpha-2$ microglobulin, C-reactive protein (CRP), haptoglobulin and serum amyloid $P(S A P)$. Eluates were used without dilution for the analysis of procalcitonin, ferritin, tissue plasminogen activator (tPA), fibrinogen and serum amyloid A (SAA). Samples were analyzed and concentrations of APPs were imputed using Bio-Plex 200 Suspension Array System with Bio-Plex Manager 6.0 software (Hercules, CA, USA). Coefficients of variation were calculated for the manufacturer-provided analytical controls. These varied by analyte from $6 \%$ to $14 \%$ (Table 1). All analytes from all blank filters were below the limit of detection. The percentage of samples analyzed that were below the lower limit of quantification (LLOQ) varied by analyte from $1 \%$ to $11 \%$ (Table 1 ). Samples below the LLOQ were assigned the value of the LLOQ/ $\sqrt{2}$ in subsequent analyses.

Covariate data. Data on maternal immigration, maternal age at birth of the child, gestational age, weight and length at birth, mode of delivery and Apgar scores were collected from the MBR. 
Table 1 Analytical statistics for measurement of nine acute phase proteins

\begin{tabular}{|c|c|c|c|}
\hline Analyte & $\begin{array}{c}\% \text { CV } \\
\text { (controls) }\end{array}$ & $\begin{array}{c}\% \text { Below } \\
\text { LLOQ }\end{array}$ & $L L O Q$ \\
\hline$\alpha-2-$ Macroglobulin & 14 & 0.6 & $0.081 \mathrm{ng} \mathrm{ml}^{-1}$ \\
\hline Haptoglobin & 11 & 1.0 & $0.026 \mathrm{ng} \mathrm{ml}^{-1}$ \\
\hline C-reactive protein & 10 & 1.2 & $0.0015 \mathrm{ng} \mathrm{ml}^{-}$ \\
\hline Serum amyloid $\mathrm{P}$ & 11 & 0.7 & $0.011 \mathrm{ng} \mathrm{ml}^{-1}$ \\
\hline Procalcitonin & 11 & 11.1 & $0.67 \mathrm{pg} \mathrm{ml}^{-1}$ \\
\hline Ferritin & 6 & 0.8 & $0.85 \mathrm{pg} \mathrm{ml}^{-1}$ \\
\hline tPA & 6 & 10.2 & $2.0 \mathrm{pg} \mathrm{ml}^{-1}$ \\
\hline Fibrinogen & 13 & 4.6 & $3.5 \mathrm{ng} \mathrm{ml}^{-1}$ \\
\hline Serum amyloid $A$ & 8 & 11.4 & $0.49 \mathrm{ng} \mathrm{ml}^{-1}$ \\
\hline
\end{tabular}

Abbreviations: LLOQ, lower limit of quantification; CV, coefficient of variation tPA, tissue plasminogen activator.

Statistical analyses. Spearman correlations were calculated for APPs. Due to skewness, APPs concentrations were $\log _{2}$-transformed for analysis; therefore, each odds ratios (OR) represents the average change in odds associated with doubling of the concentration of the biomarker. Conditional logistic regression for matched data was used to calculate OR for each $\log _{2}$-transformed APP (Model 1). Subsequent models were adjusted for maternal age ( $35+$ years), having a foreign-born mother and $\mathrm{C}$-section birth (Model 2). Model 3 adjusted for Model 2 covariates along with low Apgar $(<7$ at $5 \mathrm{~min}$ ), birth order (first child or other), gestational week ( $\geqslant 37$ or $<37$ ), small-for-gestational age and ponderal index.

Analysis of APPs as continuous variables assumes an underlying dose-response relationship and is susceptible to influence by outlying values. As a sensitivity analysis, data for each APP were divided into tertiles based on the concentration distribution among controls. Conditional logistic regression was again used to compare the middle and upper tertiles with the lowest tertile for each APP, in a model adjusted for maternal age (35 + years), having a foreign-born mother, and C-section birth.

\section{Results}

The population demographics, including the distribution of APP concentrations in filter eluates, are given in Table 2 . The correlation coefficients for the APPs ranged from 0.21 to 0.83 (Supplementary Table S1). No relation was found between APP concentrations and season of birth (Supplementary eFigure S1).

In general, risk of non-affective psychoses was reduced with increased concentrations of APPs (Table 3). Decreased risks of non-affective psychoses were associated with increasing concentrations of TPA and SAP (Table 3).

Potential confounding. Maternal-age ( $>35$ years; OR: $1.81 ; 95 \%$ confidence interval $(\mathrm{Cl}): 1.04-3.15)$ and maternal migration to Sweden (OR: 1.79; 95\% Cl: 1.14-2.83) were associated with increased risk of non-affective psychosis, while birth via caesarian section (OR: 0.47; 95\% Cl: $0.25-$ 0.92) was associated with decreased risk of non-affective psychosis. However, inclusion of these variables in the model did not affect the risk estimates for the different APPs (Table 3).
Table 2 Summary of potentially influential covariates and APPs by case and control

\begin{tabular}{|c|c|c|}
\hline Analyte & Cases $(\mathrm{n}=196)$ & Controls $(\mathrm{n}=502)$ \\
\hline Apgar $<7$ at $5 \mathrm{~min}(\%)$ & 2.3 & 1.5 \\
\hline Gestational week & $40(39-41)$ & $40(39-41)$ \\
\hline Maternal age $>35$ years $(\%)$ & 13.6 & 8.7 \\
\hline Small-for-gestational age (\%) & 5.1 & 4.7 \\
\hline C-section birth (\%) & 7.5 & 12.5 \\
\hline Foreign-born mother (\%) & 22.1 & 13.3 \\
\hline Ponderal index & $27(25-29)$ & $27(25-29)$ \\
\hline Sex (\% male) & 54 & 49 \\
\hline Year of birth & 1978 (1977-1981) & $1978(1977-1981)$ \\
\hline \multicolumn{3}{|l|}{ Acute phase proteins } \\
\hline$\alpha-2$-Macroglobulin $\left(\mathrm{ng} \mathrm{ml}^{-1}\right)$ & $347(155-630)$ & 408 (152-675) \\
\hline Haptoglobin (ng ml $\left.{ }^{-1}\right)$ & $6.75(2.78-26.2)$ & $6.27(2.48-17.0)$ \\
\hline C-reactive protein $\left(\mathrm{ng} \mathrm{ml}^{-1}\right)$ & $0.63(0.23-1.44)$ & $0.78(0.24-1.95)$ \\
\hline Serum amyloid $\mathrm{P}\left(\mathrm{ng} \mathrm{ml}^{-1}\right)^{\prime}$ & $8.91(5.03-15.3)$ & $11.0(5.46-17.7)$ \\
\hline Procalcitonin $\left(\mathrm{pg} \mathrm{ml}^{-1}\right)$ & $1.98(0.76-3.48)$ & $2.24(0.76-3.79)$ \\
\hline Ferritin (pg ml $\left.{ }^{-1}\right)$ & $1474(326-3062)$ & 1417 (372-2927) \\
\hline $\mathrm{tPA}\left(\mathrm{pg} \mathrm{ml}^{-1}\right)$ & $2.99(0.62-5.33)$ & $3.89(1.65-6.25)$ \\
\hline Fibrinogen (ng ml $\left.{ }^{-1}\right)$ & $7.62(2.31-24.4)$ & $7.62(2.31-24.4)$ \\
\hline Serum amyloid $\mathrm{A}$ (ng ml ${ }^{-1}$ ) & $1.43(0.63-2.80)$ & $1.70(0.79-3.72)$ \\
\hline
\end{tabular}

Abbreviations: APP, acute phase protein; tPA, tissue plasminogen activator. All shown as median (25th-75th percentile), unless otherwise specified.

Table 3 Risk of non-affective psychoses, using $\log _{2}$-transformed values of APPs

\begin{tabular}{lccc}
\hline & Model $1^{\mathrm{a}}$ & Model $^{\mathrm{b}}$ & Model $^{\mathrm{c}}$ \\
\hline $\begin{array}{l}\alpha-2- \\
\text { Macroglobulin }\end{array}$ & $0.91(0.79-1.04)$ & $0.91(0.79-1.06)$ & $0.93(0.79-1.10)$ \\
$\begin{array}{l}\text { Haptoglobin } \\
\text { C-reactive }\end{array}$ & $0.94(0.86-1.03)$ & $0.95(0.86-1.03)$ & $0.95(0.85-1.05)$ \\
protein & $0.94(0.86-1.03)$ & $0.93(0.85-1.02)$ & $0.94(0.85-1.04)$ \\
Serum amy- & $0.88(0.78-0.99)$ & $0.88(0.77-0.99)$ & $0.88(0.76-1.01)$ \\
loid P & & & \\
Procalcitonin & $0.94(0.86-1.03)$ & $0.95(0.86-1.04)$ & $0.92(0.83-1.03)$ \\
Ferritin & $1.02(0.91-1.15)$ & $1.03(0.91-1.16)$ & $1.03(0.90-1.19)$ \\
tPA & $0.90(0.85-0.96)$ & $0.91(0.85-0.97)$ & $0.87(0.81-0.94)$ \\
Fibrinogen & $0.97(0.91-1.03)$ & $0.97(0.91-1.03)$ & $0.96(0.89-1.03)$ \\
Serum amy- & $0.94(0.87-1.01)$ & $0.95(0.88-1.03)$ & $0.91(0.83-1.00)$ \\
loid A & & & \\
\end{tabular}

Abbreviations: APP, acute phase protein; tPA, tissue plasminogen activator. a'Matched for sex, date of birth and hospital of birth. ' $M$ Matched as in 'a', adjusted for maternal age (35 + years), foreign-born mother and C-section. ${ }^{\circ}$ Matched as in 'a', adjusted for low apgar, birth order, gestational week, maternal age (35+ years), small-for-gestational age, C-section, foreign-born mother and ponderal index.

Obstetric complications have been associated with risk of non-affective psychosis. ${ }^{29}$ In the study population, indicators such as low Apgar, birth order, gestational week, small-forgestational age and ponderal index (weight/length ${ }^{3}$ ) were not associated with risk of non-affective psychosis. Inclusion of these variables in the model did not affect the risk estimates for the different APPs (Table 3).

Tertile analysis. Tertiles were set according to the distribution of APP concentrations among controls (Supplementary Table 2). Analysis comparing risk of non-affective psychosis in upper tertiles compared with the lowest tertile (adjusted for maternal age, foreign-born mother and C-section birth) revealed patterns similar to the analysis of APPs as continuous variables. Risk of psychosis was reduced in the highest tertile of tPA and SAP compared with the lowest 
tertile (Figure 2). Additionally, risk of psychosis was reduced in the highest tertile of procalcitonin (Figure 2).

\section{Discussion}

Our data indicate that individuals who develop schizophrenia and other non-affective psychoses have lower levels of at least three different APPs as compared with controls in the neonatal period. To the best of our knowledge, this is the first study of markers of inflammation performed on neonatal samples from individuals later diagnosed with non-affective psychoses and their matched controls.

As described in the Introduction, previous studies on neonatal samples have measured total or specific immunoglobulins of subclass $G$, which are most likely derived from the maternal circulation and hence indicate previous maternal exposures. Levels of different APPs have, however, been investigated in adult individuals diagnosed with schizophrenia or other non-affective psychoses. Given the results from these studies, our findings are somewhat surprising. A number of studies have reported elevated CRP in patients with schizophrenia, ${ }^{30,31}$ though some increases in CRP in treated patient populations can be attributed to antipsychotic treatment. ${ }^{32}$ Notably, circulating CRP concentrations have been correlated with cognitive deficits in schizophrenia patients in the largest studies to date. ${ }^{33,34}$ Moreover, circulating haptoglobin, $\alpha-2$ microglobulin, SAP, CRP, and ferritin have been reported to be increased in schizophrenia patients as compared with control subjects. ${ }^{35,36}$

The overall pattern of APPs observed in the current study population indicates that individuals who will go on to develop non-affective psychoses are more likely to have lower levels of some, but not all, of the investigated APPs as compared with matched controls. The varied roles played by the specific APP's offer a number of mechanisms potentially underlying their association with a future diagnosis of non-affective psychosis.

The pentraxins and other pattern-recognition molecules. SAP and CRP both belong to a family of pattern-recognition molecules termed pentraxins. SAP and CRP are $51 \%$ homologous, though they display differences in terms of target affinity and concentration changes during the acute phase response. ${ }^{37}$ Procalcitonin is the precursor protein to

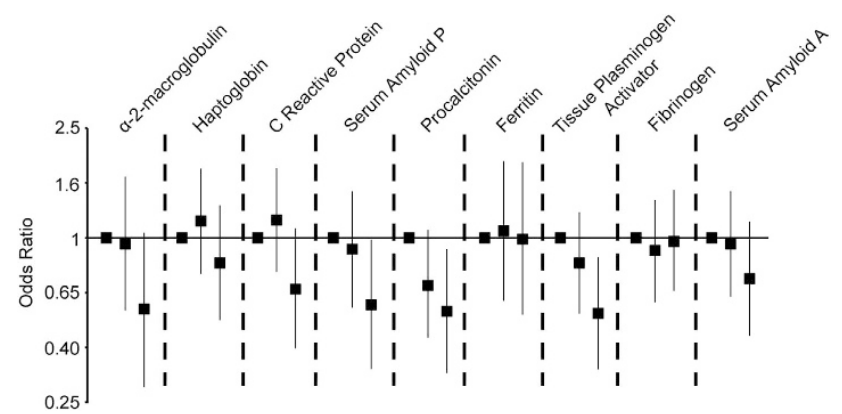

Figure 2 Risk of non-affective psychosis by tertiles of acute phase proteins, matched for sex, date of birth and hospital of birth, and adjusted for maternal age (35 + years), foreign-born mother and C-section. (Tertiles set using controls only.) Results are shown as odds ratios with $95 \%$ confidence intervals. calcitonin, a calcium-binding hormone whose physiological role in humans is poorly defined. ${ }^{38}$ Levels of procalcitonin increase more rapidly than CRP in response to endotoxic insults, and elevated procalcitonin-levels have therefore been proposed as a specific marker of systemic bacterial infections. $^{39}$

We observed that levels of SAP and procalcitonin were significantly lower among cases compared with controls, with a similar, though non-significant, trend for CRP. These findings suggest that deficits in the neonatal innate immune system are involved in the later development of non-affective psychoses. This finding is intriguing given that history of severe infections during childhood has been reported to be a risk factor for schizophrenia in some, ${ }^{40,41}$ but not all, ${ }^{42}$ studies. Additionally, schizophrenia cases are more likely to test seropositive for antibodies to specific infectious agents. ${ }^{43-46}$ It can thus be speculated that deficits in the innate immune defense may leave the neonate more vulnerable to infectious agents, potentially leading to earlier, more severe or chronic infections. Indeed, mice deficient in IL-6, the cytokine that most directly influences the acute phase response, are highly vulnerable to several infectious agents, including Toxoplasma gondii. ${ }^{47}$ Notably, mice in which the hepatic IL-6 signal transduction pathway has been knocked out suffer not only from an attenuated APP response following infection or endotoxin challenge but also increased and persistent systemic levels of pro-inflammatory cytokines, indicating that an adequate hepatic acute phase response is necessary for the appropriate resolution of inflammation. ${ }^{48}$ The discrepancy between low neonatal APP levels observed here and the elevated levels reported in adult patient populations may thus result from decades of increased risk of contracting infectious diseases. Following repeated stimulation of the proinflammatory pathways, the same pathways may become chronically activated, eventually leading to persistent elevation of acute phase reactants. ${ }^{49,50}$ The acute inflammatory response, while having a critical role in the innate immune response and host defense, can during such circumstances become destructive to host tissues.

Regulation of blood coagulation. tPA is a serine protease that is made systemically by the vascular endothelium but is also expressed widely in the human central nervous system (CNS). ${ }^{51}$ tPA cleaves plasminogen to its active plasmin form. Plasmin can degrade fibrin, thereby acting as an anticoagulant by promoting the resolution of blood clots. We also note a trend for lower $\alpha$-2-macroglobulin in cases compared with controls. $\alpha-2-$ Macroglobulin functions to both inhibit coagulation, by inhibiting thrombin, as well as to promote coagulation, by inhibiting plasmin. ${ }^{52}$ Although there was no difference between case and controls in terms of fibrinogen (which also promotes clotting), ${ }^{53}$ these data indicate that clotting is potentially dysregulated in some neonates who will later develop nonaffective psychosis. Disturbances in blood coagulability, potentially contributing to the increased incidence of cardiovascular disease among patients with schizophrenia, have not only been associated with anti-psychotic medication use but have also been reported in medication-naive patients with psychosis. ${ }^{54}$ 
Regulation of CNS development and function. In addition to its role in coagulation, tPA is also important within the CNS. In rodents, tPA is expressed in CNS tissues beginning early in development, where tPA expression is involved in neurogenesis and synaptic formation. ${ }^{55} \mathrm{~A}$ key role for IPA in CNS development and function is further supported by studies in mice lacking tPA, which display abnormalities in both emotional and cognitive domains. ${ }^{56}$

Some actions of tPA in the CNS may be mediated via actions on brain-derived neurotropic factor (BDNF). BDNF is activated from proBDNF to mature BDNF by the tPAmediated activation of plasmin. BDNF and TPA are both required for long-term potentiation, considered to be the molecular mechanism underlying learning and memory. ${ }^{57}$ Interestingly, low circulating levels of BDNF are observed in patients with schizophrenia and non-affective psychoses, with the most notable deficit in first-episode, drug-naive patients. ${ }^{58}$ Systemic levels of BDNF appear to correspond well to levels of BDNF observed in the cerebrospinal fluid in these patients. ${ }^{59}$ Our current finding of low tPA levels suggest that those who will go on to develop psychosis later in life may have a deficit in BDNF signaling well before the onset of the disease, that is, already at the time of birth.

Iron homeostasis. Ferritin binds to iron and releases it in a controlled manner. Circulating levels are directly correlated with iron stores in adults as well as neonates. ${ }^{60}$ Ferritin levels increase during an acute phase response, in order to deprive microbes of iron. ${ }^{26}$ Haptoglobin binds to hemoglobin released from erythrocytes and also functions to sequester iron during an acute phase response. ${ }^{61}$

Previous studies have linked maternal anemia, as diagnosed by low maternal hemoglobin levels, with increased risk of schizophrenia in the offspring. ${ }^{62,63}$ An implication of these studies is that perinatal iron deficiency may increase later risk of schizophrenia in the offspring because iron is necessary for many processes underlying neurodevelopment. However, we did not observe any differences between cases and controls in terms of neonatal ferritin levels. One possible explanation is that the mothers in our study population had generally good nutritional status and that severe iron deficiency was rare, thus limiting our power to detect such an effect. Data on maternal or cord blood hemoglobin levels were not available, and this possibility could not be further investigated. Only four mothers had a formal diagnosis of iron deficiency in the MBR, and children of these mothers did have relatively low ferritin levels ( $<25$ th percentile). However, it should be noted that cord serum ferritin values are on average 10 times higher than maternal serum ferritin values and that, in iron-sufficient populations, there is little relation between maternal iron status and cord blood ferritin. ${ }^{60,64}$

An alternative hypothesis is that low maternal hemoglobin may be mediating the risk of schizophrenia by increasing the risk of intrauterine hypoxia, ${ }^{62,65}$ another documented risk factor for schizophrenia. ${ }^{66,67}$ In our study, levels of the acute phase marker most closely associated with hypoxia in neonates, $\mathrm{SAA},{ }^{68}$ did not significantly differ between cases and controls. SAA, in contrast to SAP, does not act as a pattern-recognition molecule but instead has a role in the chemotactic recruitment of phagocytic cells and modulation of the extracellular matrix. If anything, cases had slightly lower SAA. However, it should be noted that only four cases and seven control individuals had an Apgar score of $<7$ at $5 \mathrm{~min}$ after birth (Table 1), indicating that few individuals in our study population suffered from neonatal hypoxia. ${ }^{67}$ Therefore, the power to detect changes in a biomarker such as SAA in response to birth complications in our study was low.

Strengths and limitations. This study is based on archived samples, collected prospectively for an entire population, preventing bias in sample collection or storage conditions. Investigators carrying out technical analyses were blinded to the case status of the samples. Thus, the results likely are not due to bias in sample collection, storage or handling. However, the small volume of the blood spots limits the number of analyses that can be performed. As we noted earlier, ${ }^{19}$ there was a relatively low participation rate in the study and more cases declined consent compared with the controls. Though selection bias cannot be completely ruled out, cases who consented to participate did not differ in age, sex or diagnosis compared with those who did not. ${ }^{19}$

A further limitation is that only a single time point in the perinatal period was captured. It remains to be investigated how these neonatal markers relate to maternal immune signals over the course of pregnancy. Unfortunately, corresponding maternal sera are not available and the role of maternal inflammatory mediators on neonatal levels of APPs cannot be investigated in the present study population. However, maternal immune reactivities to specific antigens are readily detectable in neonatal blood, and the potential role of such reactivities can therefore be investigated in future studies. Genetic variation could potentially contribute to the differences observed between cases and controls but was not investigated here. Circulating levels of, for example, CRP in adults are influenced by variation in multiple genes. ${ }^{69-71}$ However, little is known about the associations between these variants and circulating levels of APPs in younger populations, particularly at the time of birth.

\section{Conclusions}

To our knowledge, this is the first study to examine levels of APPs, which are indicators of the child's own immune response, at the time of birth, in a cohort of individuals who will go on to develop non-affective psychoses. We report that those who will go on to develop non-affective psychoses later in life appear to have lower levels of some, but not all, APPs at the time of birth. Reduced levels of pentraxins suggest increased susceptibility to infectious disease among some cases. Additionally, lower levels of tPA suggest potential deficiencies in pathways critical to neurodevelopment beginning already at the time of birth. To devise preventive strategies for non-affective psychosis, future studies are needed to investigate the mechanisms underlying the identified changes in APPs. Such studies need to consider environmental exposures as well as genetic risk factors.

\section{Conflict of interest}

The authors declare no conflict of interest. 
Acknowledgements. The present study was generously supported by the Stanley Medical Research Institute, the Swedish Research Council and the Regional Agreement on Medical Training and Clinical Research, Stockholm.

1. Mortensen $P B$, Pedersen MG, Pedersen $C B$. Psychiatric family history and schizophrenia risk in Denmark: which mental disorders are relevant? Psychol Med 2010; 40: 201-210.

2. Torrey EF, Bartko JJ, Yolken RH. Toxoplasma gondii and other risk factors for schizophrenia: an update. Schizophr Bull 2012; 38: 642-647.

3. Mortensen PB, Pedersen CB, Westergaard T, Wohlfahrt J, Ewald H, Mors $\mathrm{O}$ et al. Effects of family history and place and season of birth on the risk of schizophrenia. N Engl J Med 1999; 340: 603-608.

4. Ripke S, Sanders AR, Kendler KS, Levinson DF, Sklar P, Holmans PA et al. Genome-wide association study identifies five new schizophrenia loci. Nat Genet 2011; 43: 969-976.

5. Stefansson H, Ophoff RA, Steinberg S, Andreassen OA, Cichon S, Rujescu D et al. Common variants conferring risk of schizophrenia. Nature 2009; 460: 744-747.

6. Purcell SM, Wray NR, Stone JL, Visscher PM, O'Donovan MC, Sullivan PF et al. Common polygenic variation contributes to risk of schizophrenia and bipolar disorder. Nature 2009; 460: 748-752.

7. Jia $\mathrm{P}$, Wang $\mathrm{L}$, Fanous $\mathrm{AH}$, Chen $\mathrm{X}$, Kendler $\mathrm{KS}$, Zhao Z. A bias-reducing pathway enrichment analysis of genome-wide association data confirmed association of the MHC region with schizophrenia. J Med Genet 2012; 49: 96-103.

8. Shi J, Levinson DF, Duan J, Sanders AR, Zheng Y, Pe'er I et al. Common variants on chromosome 6p22.1 are associated with schizophrenia. Nature 2009; 460: 753-757.

9. Hamshere ML, Walters JT, Smith R, Richards AL, Green E, Grozeva D et al. Genome-wide significant associations in schizophrenia to ITIH3/4, CACNA1C and SDCCAG8, and extensive replication of associations reported by the Schizophrenia PGC. Mol Psychiatry advance online publication, 22 May 2012; doi:10.1038/mp.2012.67.

10. Eaton WW, Byrne M, Ewald H, Mors O, Chen CY, Agerbo E et al. Association of schizophrenia and autoimmune diseases: linkage of Danish national registers. Am J Psychiatry 2006; 163: 521-528.

11. Benros ME, Nielsen PR, Nordentoft M, Eaton WW, Dalton SO, Mortensen PB. Autoimmune diseases and severe infections as risk factors for schizophrenia: a 30-year population-based register study. Am J Psychiatry 2011; 168: 1303-1310.

12. Chen SJ, Chao YL, Chen CY, Chang CM, Wu EC, Wu CS et al. Prevalence of autoimmune diseases in in-patients with schizophrenia: nationwide population-based study. $\mathrm{Br} \mathrm{J}$ Psychiatry 2012; 200: 374-380

13. Miller BJ, Buckley P, Seabolt W, Mellor A, Kirkpatrick B. Meta-analysis of cytokine alterations in schizophrenia: clinical status and antipsychotic effects. Biol Psychiatry 2011; 70: $663-671$.

14. van Berckel BN, Bossong MG, Boellaard R, Kloet R, Schuitemaker $A$, Caspers $E$ et al. Microglia activation in recent-onset schizophrenia: a quantitative (R)-[11C]PK11195 positron emission tomography study. Biol Psychiatry 2008; 64: 820-822.

15. Lee SH, DeCandia TR, Ripke S, Yang J, Sullivan PF, Goddard ME et al. Estimating the proportion of variation in susceptibility to schizophrenia captured by common SNPs. Nat Genet 2012; 44: 247-250

16. Brown AS, Cohen P, Greenwald S, Susser E. Nonaffective psychosis after prenatal exposure to rubella. Am J Psychiatry 2000; 157: 438-443

17. Buka SL, Cannon TD, Torrey EF, Yolken RH. Maternal exposure to herpes simplex virus and risk of psychosis among adult offspring. Biol Psychiatry 2008; 63: 809-815.

18. Mortensen PB, Norgaard-Pedersen B, Waltoft BL, Sorensen TL, Hougaard D, Torrey EF et al. Toxoplasma gondii as a risk factor for early-onset schizophrenia: analysis of filter paper blood samples obtained at birth. Biol Psychiatry 2007; 61: 688-693.

19. Karlsson H, Blomstrom A, Wicks S, Yang S, Yolken RH, Dalman C. Maternal antibodies to dietary antigens and risk for nonaffective psychosis in offspring. Am J Psychiatry 2012; 169: 625-632

20. Brown AS, Hooton J, Schaefer CA, Zhang H, Petkova E, Babulas V et al. Elevated maternal interleukin-8 levels and risk of schizophrenia in adult offspring. Am J Psychiatry 2004; 161: 889-895.

21. Buka SL, Tsuang MT, Torrey EF, Klebanoff MA, Wagner RL, Yolken RH. Maternal cytokine levels during pregnancy and adult psychosis. Brain Behav Immun 2001; 15 : 411-420.

22. Meyer U, Feldon J. Epidemiology-driven neurodevelopmental animal models of schizophrenia. Prog Neurobiol 2010; 90: 285-326.

23. Deverman BE, Patterson PH. Cytokines and CNS development. Neuron 2009; 64: 61-78.

24. Hsiao EY, Patterson PH. Activation of the maternal immune system induces endocrine changes in the placenta via IL-6. Brain Behav Immun 2011; 25: 604-615.

25. Heinrich PC, Castell JV, Andus T. Interleukin-6 and the acute phase response. Biochem J 1990; 265: 621-636.

26. Gabay C, Kushner I. Acute-phase proteins and other systemic responses to inflammation. N Engl J Med 1999; 340: 448-454.

27. Bauer J, Lengyel G, Thung SN, Jonas U, Gerok W, Acs G. Human fetal hepatocytes respond to inflammatory mediators and excrete bile. Hepatology 1991; 13: 1131-1141.

28. de Villiers WJ, Louw JP, Strachan AF, Etsebeth SM, Shephard EG, de Beer FC. C-reactive protein and serum amyloid A protein in pregnancy and labour. Br J Obstet Gynaecol 1990; 97: $725-730$.
29. Cannon M, Jones PB, Murray RM. Obstetric complications and schizophrenia: historical and meta-analytic review. Am J Psychiatry 2002; 159: 1080-1092.

30. Fawzi MH, Fawzi MM, Fawzi MM, Said NS. C-reactive protein serum level in drug-free male Egyptian patients with schizophrenia. Psychiat Res 2011; 190: 91-97.

31. Fan X, Pristach C, Liu EY, Freudenreich O, Henderson DC, Goff DC. Elevated serum levels of $\mathrm{C}$-reactive protein are associated with more severe psychopathology in a subgroup of patients with schizophrenia. Psychiat Res 2007; 149: 267-271.

32. Meyer JM, McEvoy JP, Davis VG, Goff DC, Nasrallah HA, Davis SM et al. Inflammatory markers in schizophrenia: comparing antipsychotic effects in phase 1 of the clinical antipsychotic trials of intervention effectiveness study. Biol Psychiatry 2009; 66 : 1013-1022.

33. Dickerson F, Stallings C, Origoni A, Boronow J, Yolken R. C-reactive protein is associated with the severity of cognitive impairment but not of psychiatric symptoms in individuals with schizophrenia. Schizophr Res 2007; 93: 261-265.

34. Dickerson F, Stallings C, Origoni A, Vaughan C, Khushalani S, Yolken R. Additive effects of elevated C-reactive protein and exposure to Herpes Simplex Virus type 1 on cognitive impairment in individuals with schizophrenia. Schizophr Res 2012; 134: 83-88.

35. Wong CT, Tsoi WF, Saha N. Acute phase proteins in male Chinese schizophrenic patients in Singapore. Schizophr Res 1996; 22: 165-171.

36. Chan MK, Guest PC, Levin Y, Umrania Y, Schwarz E, Bahn S et al. Converging evidence of blood-based biomarkers for schizophrenia: An update. Int Rev Neurobiol 2011; 101: 95-144.

37. Inforzato A, Bottazzi B, Garlanda C, Valentino S, Mantovani A. Pentraxins in humoral innate immunity. Adv Exp Med Biol 2012; 946: 1-20.

38. Becker KL, Nylen ES, White JC, Muller B, Snider Jr RH. Clinical review 167: procalcitonin and the calcitonin gene family of peptides in inflammation, infection, and sepsis: a journey from calcitonin back to its precursors. J Clin Endocrinol Metab 2004; 89: 1512-1525.

39. van Rossum AM, Wulkan RW, Oudesluys-Murphy AM. Procalcitonin as an early marker of infection in neonates and children. Lancet Infect Dis 2004; 4: 620-630.

40. Dalman C, Allebeck P, Gunnell D, Harrison G, Kristensson K, Lewis G et al. Infections in the CNS during childhood and the risk of subsequent psychotic illness: a cohort study of more than one million Swedish subjects. Am J Psychiatry 2008; 165: 59-65.

41. Koponen H, Rantakallio P, Veijola J, Jones P, Jokelainen J, Isohanni M. Childhood central nervous system infections and risk for schizophrenia. Eur Arch Psychiatry Clin Neurosci 2004; 254: 9-13.

42. Weiser M, Werbeloff N, Levine A, Livni G, Schreiber S, Halperin D et al. CNS infection in childhood does not confer risk for later schizophrenia: a case-control study. Schizophr Res 2010; 124: 231-235.

43. Torrey EF, Yolken RH. Toxoplasma gondii and schizophrenia. Emerg Infect Dis 2003; 9: $1375-1380$.

44. Niebuhr DW, Millikan AM, Cowan DN, Yolken R, Li Y, Weber NS. Selected infectious agents and risk of schizophrenia among U.S. military personnel. Am J Psychiatry 2008; 165: 99-106

45. Pedersen MG, Stevens H, Pedersen CB, Norgaard-Pedersen B, Mortensen PB. Toxoplasma infection and later development of schizophrenia in mothers. Am J Psychiatry 2011; 168: 814-821.

46. Leweke FM, Gerth CW, Koethe D, Klosterkotter J, Ruslanova I, Krivogorsky B et al. Antibodies to infectious agents in individuals with recent onset schizophrenia. Eur Arch Psychiatry Clin Neurosci 2004; 254: 4-8.

47. Suzuki Y, Rani S, Liesenfeld O, Kojima T, Lim S, Nguyen TA et al. Impaired resistance to the development of toxoplasmic encephalitis in interleukin-6-deficient mice. Infect Immun 1997; 65: 2339-2345.

48. Sander LE, Sackett SD, Dierssen U, Beraza N, Linke RP, Muller M et al. Hepatic acutephase proteins control innate immune responses during infection by promoting myeloidderived suppressor cell function. J Exp Med 2010; 207: 1453-1464.

49. Gabay C. Interleukin-6 and chronic inflammation. Arthritis Res Ther 2006; 8(Suppl 2): S3

50. Marschan E, Kuitunen M, Kukkonen K, Poussa T, Sarnesto A, Haahtela T et al. Probiotics in infancy induce protective immune profiles that are characteristic for chronic low-grade inflammation. Clin Exp Allergy 2008; 38: 611-618.

51. Teesalu T, Kulla A, Simisker A, Siren V, Lawrence DA, Assera T et al. Tissue plasminogen activator and neuroserpin are widely expressed in the human central nervous system. Thromb Haemost 2004; 92: 358-368.

52. de Boer JP, Creasey AA, Chang A, Abbink JJ, Roem D, Eerenberg AJ et al. Alpha-2macroglobulin functions as an inhibitor of fibrinolytic, clotting, and neutrophilic proteinases in sepsis: studies using a baboon model. Infect Immun 1993; 61: 5035-5043.

53. Blomback B, Hessel B, Hogg D, Therkildsen L. A two-step fibrinogen-fibrin transition in blood coagulation. Nature 1978; 275: 501-505.

54. Masopust J, Maly R, Andrys C, Valis M, Bazant J, Hosak L. Markers of thrombogenesis are activated in unmedicated patients with acute psychosis: a matched case control study. BMC psychiatry 2011; 11: 2.

55. Friedman GC, Seeds NW. Tissue plasminogen activator expression in the embryonic nervous system. Brain Res Dev Brain Res 1994; 81: 41-49.

56. Pothakos K, Robinson JK, Gravanis I, Marsteller DA, Dewey SL, Tsirka SE. Decreased serotonin levels associated with behavioral disinhibition in tissue plasminogen activator deficient (tPA-/-) mice. Brain Res 2010; 1326: 135-142.

57. Poo MM. Neurotrophins as synaptic modulators. Nat Rev Neurosci 2001; 2: 24-32. 
58. Buckley PF, Pillai A, Howell KR. Brain-derived neurotrophic factor: findings in schizophrenia. Curr Opin Psychiatry 2011; 24: 122-127.

59. Pillai A, Kale A, Joshi S, Naphade N, Raju MS, Nasrallah H et al. Decreased BDNF levels in CSF of drug-naive first-episode psychotic subjects: correlation with plasma BDNF and psychopathology. Int J Neuropsychopharmacol 2010; 13: 535-539.

60. Siddappa AM, Rao R, Long JD, Widness JA, Georgieff MK. The assessment of newborn iron stores at birth: a review of the literature and standards for ferritin concentrations. Neonatology 2007; 92: 73-82.

61. Levy AP, Asleh R, Blum S, Levy NS, Miller-Lotan R, Kalet-Litman S et al. Haptoglobin: basic and clinical aspects. Antioxid Redox Signal 2010; 12: 293-304.

62. Insel BJ, Schaefer CA, McKeague IW, Susser ES, Brown AS. Maternal iron deficiency and the risk of schizophrenia in offspring. Arch Gen Psychiatry 2008; 65: 1136-1144.

63. Sorensen HJ, Nielsen PR, Pedersen CB, Mortensen PB. Association between prepartum maternal iron deficiency and offspring risk of schizophrenia: population-based cohort study with linkage of Danish national registers. Schizophr Bull 2011; 37: 982-987.

64. Tchernia G, Archambeaud MP, Yvart J, Diallo D. Erythrocyte ferritin in human neonates: maternofetal iron kinetics revisited. Clin Lab Haematol 1996; 18: 147-153.

65. Viteri FE. The consequences of iron deficiency and anemia in pregnancy. Adv Exp Med Biol 1994; 352: 127-139.

66. Zornberg GL, Buka SL, Tsuang MT. Hypoxic-ischemia-related fetal/neonatal complications and risk of schizophrenia and other nonaffective psychoses: a 19-year longitudinal study. Am J Psychiatry 2000; 157: 196-202.
67. Dalman C, Thomas HV, David AS, Gentz J, Lewis G, Allebeck P. Signs of asphyxia at birth and risk of schizophrenia. Population-based case-control study. Br J Psychiatry 2001; 179: 403-408.

68. Aly H, Hamed Z, Mohsen L, Ramy N, Arnaoot H, Lotfy A. Serum amyloid A protein and hypoxic ischemic encephalopathy in the newborn. J Perinatol 2011; 31: 263-268.

69. Reiner AP, Wurfel MM, Lange LA, Carlson CS, Nord AS, Carty CL et al. Polymorphisms of the IL1-receptor antagonist gene (IL1RN) are associated with multiple markers of systemic inflammation. Arterioscler Thromb Vasc Biol 2008; 28: 1407-1412.

70. Ben Assayag E, Shenhar-Tsarfaty S, Bova I, Berliner S, Usher S, Peretz H et al. Association of the $-757 \mathrm{~T}>\mathrm{C}$ polymorphism in the CRP gene with circulating C-reactive protein levels and carotid atherosclerosis. Thromb Res 2009; 124: 458-462.

71. Lakoski SG, Li L, Langefeld CD, Liu Y, Howard TD, Brosnihan KB et al. The association between innate immunity gene (IRAK1) and C-reactive protein in the Diabetes Heart Study. Exp Mol Pathol 2007; 82: 280-283.

(c) Translational Psychiatry is an open-access journal published by Nature Publishing Group. This work is licensed under the Creative Commons Attribution-NonCommercialShare Alike 3.0 Unported License. To view a copy of this license, visit http://creativecommons.org/licenses/by-nc-sa/3.0/

Supplementary Information accompanies the paper on the Translational Psychiatry website (http://www.nature.com/tp) 